\title{
Sınıf Öğretmeni Adaylarının Sosyal Medya Bağımlılık Düzeylerinin Bazı Değişkenlere Göre İncelenmesi
}

\author{
Edip Tut*, Ceren Çevik Kansu**
}

DOI: $10.35675 /$ befdergi. 748339

$\ddot{O} z$

$B u$ araştırmada sınıf ögretmenliği ögrencilerinin sosyal medya bağımlılık düzeylerinin, çeşitli değişkenler açısından incelenmesi amaçlanmıştır. Tarama modelinde yürütülen bu çalışmanın araştırma evrenini 2019-2020 eğitim-öğretim yllında bir devlet üniversitesinin Eğitim Fakültesi'nde bulunan sinıf öğretmenliği ögrrencileri oluşturmaktadır. Veri toplama aracı olarak "Sosyal Medya Bağımlılık Ölçeği” kullanılmıştır. Verilerin analizinde Kruskal Wallis $H$ testi, bağımsız gruplar için $t$ testi ile Mann Whitney $U$ testi kullanılmıştır. Araştırmada, sınıf öğretmenliği öğrencilerinin sosyal medya bağımlılık düzeylerinin sınıf seviyesine göre farklılaşmadiğg; not ortalaması üçün üstünde olan öğrencilerin ölçekten aldıkları puanların aritmetik ortalamasının not ortalaması üçün altında olan ögrencilere oranla daha yüksek olduğu fakat bu farkın anlamlı olmadığı tespit edilmiştir. Ayrıca ayda bir kitaptan fazla okuyan sını öğretmenliği öğrencilerinin ayda bir kitap ve daha azını okuyan ögrencilere oranla daha düşük sosyal medya bağımlılı̆̆ına sahip olduğu sonucuna ulaşılmıştır.

Anahtar Kelimeler: Sını öğretmenliği, sını öğretmeni adayl, sosyal medya, sosyal medya bă̆ımlılı̆̆

\section{Examination of Social Media Addiction Levels of Preservice Classroom Teachers According to Some Variables}

\begin{abstract}
The aim of this study was to determine the effect of grade level, grade point average GPA, and the average number of books read in a year on social media addiction among preservice classroom teachers. The study population of the study carried out in the scanning model consisted of all students of the department of classroom education of a public university within the 2019-2020 academic year. Data were collected using the Social Media Addiction Scale (SMAS) and analyzed using an independent groups t test, and the Kruskal Wallis H and Mann Whitney U tests. Participants' SMAS scores did not significantly differ by grade level. Participants with a GPA greater than 3 had a higher arithmetic SMAS score than those with a

*Ondokuz Mayıs Üniversitesi, Eğitim Fakültesi, Temel Eğitim Bölümü, Sınıf Eğitimi Anabilim Dalı, Samsun, Türkiye, ediptut@ @otmail.com, ORCID: 0000-0003-2191-6539 it

** Ondokuz Mayıs Üniversitesi, Eğitim Fakültesi, Temel Eğitim Bölümü, Sınıf Eğitimi Anabilim Dal1, Samsun, Türkiye, ceren.ckansu@ omu.edu.tr, ORCID:0000-0003-4444-7165 D

Kaynak Gösterme: Tut, E., \& Çevik Kansu, C. (2021). Sınıf öğretmeni adaylarının sosyal medya bağımlılık düzeylerinin bazı değişkenlere göre incelenmesi. Bayburt Eğitim Fakültesi Dergisi, 16(32), 443-459.
\end{abstract}


GPA less than 3, which was however statistically insignificant. On the other hand, participants who read more than one book per month had significantly lower SMAS scores than those who read one book or less per month.

Keywords: Classroom teaching, preservice classroom teacher, social media, social media addiction

\section{Giriș}

İletişim, geçmişten günümüze, sosyal bir varlık olan insanın hayatında en önemli ihtiyaçlardan biri olmuştur. İletişim kurma becerisi bireylerin duygu, düşünce aktarımını sağlamakta ve toplumsallaşmaya hizmet etmektedir (İliş, 2018). Birbirleri ile daima iletişim kurma ihtiyacı içinde olan (Alican \& Saban, 2013) insanların bireyler arası iletişimi belirli kanallarla sağlanmaktadır. İletişimi sağlayan bu kanallar ise zaman içerisinde yaşanan gelişmelerden etkilenmiş, değişmiştir. İnsanların iletişim biçimini etkileyen en büyük etmenlerin teknoloji ve internet olduğu kabul edilmektedir. Özellikle internetin icadı ve kullanımının artmasıyla insanlar arası iletişimi sağlayabilecek ve kolaylaştırabilecek birçok farklı platform ortaya çıkmıştır. Yaşanan bu gelişmelerle toplumun dijitalleşmeye doğru yöneldiği ve dolayısıyla da sosyal ilişkilerin de dijital alana transfer edildiği görülmektedir.

20. yüzyılın en önemli olaylarından biri de internetin bulunması ve insanlığın hizmetine sunulması olduğu düşünülmektedir (Solmaz, Tekin, Herzem \& Demir, 2013). İnternet, eşzamanlı ve mekândan bağımsız bir şekilde bilgisayar ağlarının, büyük kitleleri sanal dünyada birleştirebileceği tarzda dev bir ortamı oluşturmuştur (Y1lmazsoy \& Kahraman, 2017). İnternetin bu getirileri; insanların hızlı ve etkili bir iletişim sürecine girmelerine, ihtiyaç ve ilgi alanlarına göre o alanlardaki gelişmeleri takip edebilmelerine, kendi deneyim ve görüşlerini diğer kullanıcılarla paylaşabilmelerine imkân tanımaktadır (Sarsar, Başbay \& Başbay, 2015).

1995 yılında kullanılmaya başlanan ve internetin ilk aşamasını oluşturan Web 1.0 kavramı insanların, bilgileri edilgen bir şekilde ve tek yönlü olarak almasını sağlayan (Ergenç, 2011) sanal ortamları ifade etmektedir. Web 1.0 temelli sanal ortamlarda kullanıcılar sadece okuyucu ve belirli kanallardan aktarılan bilginin alıcıs1 konumundaydı (Alican \& Saban, 2013). İleriki dönemlerde ise Web 2.0'1n ortaya çıkışı ile Web 1.0'ın tek yönlülüğü yıkılmış ve bu gelişme çift yönlü bilgi akışına olanak sağlamıştır. Bu yönde evrimleşen teknoloji; sahip olduğu etkileşim platformlarıyla iletişim sürecini tek yönlülükten kurtarmış, çok yönlü, demokratik ve eşit düzeyde imkân tanıyan 'iletişim'e dönüştürmüştür (Tuncer, 2013). Web 2.0, kullanıcıların içerik paylaşımı yapabildikleri, içeriklere müdahale edebildiği ve dönütler alabildiği sanal ortamlar olarak tanımlanmaktadır (Bat, 2012). Sanal ortamlar, Web 2.0 teknolojisi ile diğer kullanıcılar ve ağlar ile etkileşime girilmesine ve bireylerin daha aktif olmasına imkân veren dinamik bir yapı haline gelmiştir (Ergenç, 2011). 
Sosyal ağ siteleri, Web 2.0 teknolojisinin önemli bileşenlerinden biri olarak karşımıza çıkmaktadır (Karal \& Kokoç, 2010). Hatta bazı araştırmacılar (Mason \& Rennie, 2008) Web 2.0 ile sosyal medya kavramlarının veya Web 2.0 ile sosyal yazılım kavramlarının (Ellison \& Boyd, 2013; Ravenscroft, 2009) birbiri yerine kullanılabilecek kavramlar olduğunu belirtmişlerdir. Brown (2012) ise Web 2.0'1 sosyal Web olarak tanımlamıştır. Tüm bu tanımlamaların ortak noktası olan sosyallik, Web 2.0 temeline dayanan sanal ortamların iletişim biçimimize etkisini anlamamız noktasinda bize ipucu vermektedir.

Web 2.0 teknolojisi ile hayatımıza giren sosyal medya; topluluğu merkeze alan Web sitelerinde bilgi, deneyim ve görüşlerin paylaşılmasıyla alakalıdır (Küçükali, 2016). Sosyal medya, zaman ve mekândan bağımsız olarak, paylaşmanın ve tartışmanın esas olduğu insani bir iletişim biçimidir (Vural \& Bat, 2010) ve özgünlüğü, kişilerin içerik yaratabilmesi, var olan içeriklere yorumda bulunabilmesi veya katkı sağlayabilmesinden kaynaklanmaktadır (Scott, 2010). Joosten'e (2012) göre sosyal medya kavramı geniş bir anlam taşımakta ve etkileşim ve iletişime bağlı her türlü teknolojik sistemi kapsamaktadır.

Sosyal medya kavramının daha net anlaşılabilmesi için sosyal medya araçlarının bilinmesinin gerekli olduğu düşünülmektedir. Hayatımızın vazgeçilmez bir parçası haline gelen sosyal medya araçları birçok araştırmacı tarafından gruplara ayrılarak belirtilmiştir (Akar, 2010; Greenhow, 2011; Gruzd, Staves \& Wilk, 2012; Kaplan \& Haenlein, 2010). İlgili literatürden yola çıkarak; Facebook, LinkedIn gibi sosyal ağların, bloglar ve Twitter gibi miniblogların, wikilerin, Foursquare ve Delicious gibi sosyal işaretleme sitelerinin, Youtube gibi medya paylaşım sitelerinin, Slideshare gibi sunum paylaşım sitelerinin ve PubG gibi sanal oyun dünyalarının sosyal medya kapsamında değerlendirildiği söylenebilir.

Teknolojinin giderek kişi ve toplum arasındaki ilişkiye odaklanması, bireylerin sosyalleşme tarzlarında değişikliğe neden olmuş ve yeni bir sosyalleşme tarzının doğumuna zemin hazırlamıştır (Aydın, 2016). Sosyal ağlar ve sosyal medya gibi kavramların ortaya çıktığı günümüzde bireyler yeni arkadaşlar, yeni iş bağlantıları ve hatta evliliklerini bile gerçekleştirir hale gelmiştir (Özşahin, 2019). Günümüzde özellikle genç nüfusun birbirleri arasındaki iletişimi büyük oranda sosyal ağ siteleri vasıtasıyla gerçekleşmekte ve bu sitelere olan ilgi gün geçtikçe artmaktadır (Ahn, 2011). Kullanımı hızla yaygınlaşan sosyal medya ortamlarında farklı zaman dilimlerinde ve farklı mekânlarda bulunan kişilerin, dünyanın neresinde olursa olsunlar eş zamanlı bir şekilde karşılıklı olarak, sözcükler, görseller ve videolar ile etkileşim halinde olabilmelerini sağlamakta, geniş kitleleri ve farklı yaş gruplarından bireyleri etkisi altına almaktadır (Soysal, 2019).

Ülkemizde yapılan çalışmalarda da sosyal medya kullanma yaşına yönelik veriler yer almaktadır. İçirgin (2018), yaptığı çalışmada sosyal medyanın üniversite öğrencileri arasında yüksek düzeyde kullanıldığını belirtmiştir. Öte yandan Aydın (2016) tarafından 4000'den fazla katılımcı ile gerçekleştirilen çalışmada da internet 
kullanıcılarının büyük çoğunluğunun 16-24 yaş aralığında olduğu ve internet kullanımı ile sosyal medya kullanımı arasında anlamlı bir ilişkinin olduğu belirtilmiştir. Sosyal medya kullanım yaşının özellikle lise ve üniversite çağındaki gençler arasında yoğunlaştığı görülmekte ve bu durum, sosyal medya kullanımının, bu yaş aralığındaki bireyler özelinde eğitim açısından avantaj ve dezavantajlarının araştırılmasını gerekli kılmaktadır. Haberleşme, sosyalleşme ve bilgi edinme gibi noktalarda fayda sağladığı bilinen sosyal medyanın fazla kullanımının, sosyal medya bağımlılığına neden olduğu bilinmektedir. Günay (2017) Trakya Üniversitesi Tıp, Sağlık Bilimleri, Eczacılık, Diş Hekimliği Fakültelerinde öğrenim gören 1507 lisans öğrencisinin sosyal medya bağımlılık düzeylerinin belirlenmesi ve sosyo-demografik özellikler, benlik saygı düzeyleri, üniversite uyum düzeyleri ile sosyal medya bağımlılığı arasındaki ilişkiyi incelemek amacıyla bir çalışma yapmıştır. Çalışma sonucunda, sosyal medya kullanan katılımciların 1041'inde (\%70,7) sosyal medya bağımlılığı olduğu tespit edilmiştir. Sosyal medya bağımlılığı ile ilgili yapılan çalışmalarda, bu bağımlılığın hayatı olumsuz etkilediği, bireylerin uykusuz kalarak günlük işlerini aksattığı, evlilik hayatı ile ilgili problemlere yol açtığı ortaya konulmuştur (Çam \& İşbulan, 2012; Kuss \& Griffiths, 2011; Tutgun-Ünal, 2015). Ayrıca Balcı ve Gölcü (2013) tarafından yapılan bir araştırmada bireylerin yalnızlık seviyeleri ile sosyal medya kullanım süresi arasında anlamlı bir ilişkinin olduğu, sanal ortamda sosyalleşmeye çalışan bireyin gerçek hayatta daha yalnız olduğu belirtilmiştir.

Bireylerin hayatında bu denli önemli bir yere sahip olduğu düşünülen sosyal medyanın, insan hayatının her boyutuna etki edebileceği aşikârdır. Bu boyutlardan bir tanesi de eğitim ve öğrencilerin akademik başarısıdır. Eğitimin, okulların yanında iş yerinde, sokakta, oyun oynarken, ailede kısaca her yerde gerçekleşen bir olgu olduğu (Kıroğlu, 2014) düşünüldüğünde, bireylerin hayatında yer edinen sosyal medyanın da eğitime etki edebileceği düşünülmektedir. Literatür incelendiğinde, farklı yaş gruplarına yönelik sosyal medya ve eğitim ilişkisini ele alan çalışmaların bulunduğu (Al-Menayes, 2015; Apuke, 2016; Asemah, Okpanachi \& Edegoh, 2013; Chris, 2015; Çarkç1, 2019; Flanigan \& Babchuk, 2015; Giunchiglia, Zeni, Gobbi, Bignotti \& Bison., 2018; Habes, Alghizzawi, Khalaf, Salloum \& Ghani, 2018; Leyrer-Jackson \& Wilson, 2018; Owusu-Acheaw \& Larson, 2015) fakat sınıf öğretmenliği öğrencileri özelinde sosyal medya bağımlılık düzeyi ile akademik başarı ve kitap okuma alışkanlığını ele alan herhangi bir çalışmanın olmadığı görülmüştür. Bu sebeple bu çalışmanın, belirtilen alanda ilk olması sebebiyle önem arz ettiği düşünülmektedir.

Araştırmada sosyal medyanın, boş zaman geçirmek için kullanılabilecek bir araç olduğu ve bu durumun sınıf öğretmenliği öğrencilerinin akademik başarısına etki edebileceği düşünüldüğünden akademik başarı değişkeni çalışmaya dahil edilmiştir. Bununla birlikte kitap okuma oranının sosyal medya kullanma sıklığını ve dolayısıyla da sosyal medya bağımlılığını etkileyeceği düşünülmüş ve yıllık ortalama olarak okunan kitap sayısı değişkeni araştırmaya dahil edilmiştir. Son olarak da her sınıf düzeyinin ders yoğunluğunun ve gerektirdiği sorumlulukların farklı olabileceği ve bu 
durumun sosyal medya bağımlılık düzeyini etkileyebileceği düşünüldüğünden sınıf düzeyi değişkeni de araştırmada işe koşulmuştur.

$\mathrm{Bu}$ çalışmanın genel amacı sınıf öğretmenliği öğrencilerinin sosyal medya bağımlılık düzeylerinin sınıf düzeyi, not ortalaması ve okudukları kitap sayısı değişkenlerine göre incelenmesidir. $\mathrm{Bu}$ amaç doğrultusunda araştırmanın alt problemleri şu şekilde sıralanabilir:

1.Sınıf öğretmeni adaylarının sosyal medya bağımlılıkları ne düzeydedir?

2.Sınıf öğretmeni adaylarının sosyal medya bağımlılık düzeyleri sınıf düzeyine göre farklılaşmakta mıdır?

3.Sınıf öğretmeni adaylarının sosyal medya bağımlılık düzeyleri genel ağırlıklı not ortalamalarına göre farklılaşmakta mıdır?

4.Sınıf öğretmeni adaylarının sosyal medya bağımlılık düzeyleri yıllık ortalama olarak okudukları kitap sayısına göre farklılaşmakta mıdır?

\section{Yöntem}

\section{Araştırmanın Modeli}

$\mathrm{Bu}$ araştırmada, büyük kitlelerin araştırmaya konu olan özelliklerini ortaya koymayı ve betimlemeyi amaçlayan (Can, 2018) tarama modeli işe koşulmuştur. Best ve Kahn (2017) tarafindan betimsel araştırmalar olarak da tanımlanan tarama modelindeki araştırmalar, günümüzde veya öncesindeki bir durumu olduğu şekliyle ortaya koymayı amaç edinen araştırma türleridir (Karasar, 2014). Bu tip araştırmalarda olaylar ve şartlar zaten meydana gelmiş olduğundan araştırmacılar sadece var olan durumu ortaya koyabilme adına bağımsız değişkenleri belirleyebilmekte ve durumu o değişkenlere göre inceleyebilmektedir (Best \& Kahn, 2017). Bu çalışmada da bağımsız değişkenler araştırmacı tarafindan belirlenmiş ve sınıf öğretmenliği öğrencilerinin sosyal medya bağımlılığı o değişkenlere göre incelenmiştir.

\section{Evren ve Örneklem}

Araştırmanın evrenini 2019-2020 eğitim-öğretim yılının güz döneminde Türkiye'de bir devlet üniversitesinin Sınıf Eğitimi Anabilim Dalı'nda, 2., 3. ve 4. sınıflarda öğrenim gören sınıf öğretmenliği öğrencileri oluşturmaktadır. Araştırmanın evreninin tümüne ulaşmak mümkün olduğundan örneklem belirleme yoluna gidilmemiştir. Sinıf öğretmeni adaylarının sosyal medya bağımlılık düzeyleri akademik başarı değişkenine göre incelenirken genel not ortalaması dikkate alındığından birinci sınıf öğrencileri çalışmaya dahil edilmemiştir. $\mathrm{Bu}$ öğrencilerin çalışmaya dahil edilmemelerinin sebebi henüz herhangi bir not ortalamalarının bulunmamasıdır. Bununla birlikte sürekli devamsızlık yapan ve son sınıfta yer alıp üstten ders alarak son sene dersleri olmadığı için okula gelmeyen öğrenciler de çalışma kapsamına 
alınmamıştır. Son durumda çalışmaya; 2. sınıfta öğrenim gören 81,3 . sınıfta öğrenim gören 61 ve 4 . sınıfta öğrenim gören 51 sınıf öğretmeni adayı dahil edilmiştir. Çalışma kapsamında toplam 193 öğrenciye ulaşılmıştır.

\section{Verilerin Toplanması}

Araştırmada veri toplama aracı olarak Tutgun-Ünal (2015) tarafından geliştirilen "Sosyal Medya Bağımlılık Ölçeği (SMBÖ)" kullanılmıştır. Üniversite öğrencilerinin sosyal medya bağımlılıklarını ölçebilme adına geliştirilen bu ölçme aracı 41 maddeden oluşan beşli likert tipi bir ölçektir. Geçerlik çalışması 775 üniversite öğrencisi ile yapılan ölçeğin iç tutarlılık katsayısı araştırmacı tarafından ,967 bulunmuştur. Sosyal Medya Bağımlılık Ölçeği'nden alınabilecek en yüksek puanın 205, en düşük puanın ise 41 olduğu belirtilmektedir.

Sosyal Medya Bağımlılık Ölçeği’ne ek olarak öğrencilerden not ortalamaları ve yıllık ortalama olarak okudukları kitap sayılarını belirtmeleri istenmiştir. Elde edilen veriler doğrultusunda grup sayılarının birbirine denk olabilmeleri adına örneklemde yer alan sınıf öğretmeni adayları not ortalamaları üç ve üçün altında olanlar ile üçün üstünde olanlar olmak üzere ikiye ayrılmıştır. Bu durumda çalışmada, not ortalaması üç ve üçün altında olan 101, üçün üstünde olan 92 öğrenci yer almaktadır. Aynı şekilde yıllık ortalama okunan kitap sayısı da değerlendirildiğinde grup sayılarının denk olabilmesi adına yılda 0-12 kitap okuyanlar (ayda bir kitap ve altı) ve 12'den fazla kitap okuyanlar (ayda bir kitaptan fazla) olmak üzere iki grup oluşturulmuştur. Okunan kitap sayısına göre grupların oluşturulmasında öğrenci ifadeleri dikkate alınmıştır. Öğrencilerin okudukları kitap sayılarının yılda 12 kitap ve üstü şeklinde temelde iki farklı özellik gösterdiği tespit edilmiş ve bunun dışında yapılacak herhangi bir gruplandırmada grupların sayıca denkliğinin sağlanamayacağı görülmüştür. Dolayısıyla okunan kitap sayısı dikkate alındığında yılda 0-12 arası kitap okuyanlar ve 12 'nin üstünde okuyanlar olmak üzere iki grup oluşturulmuştur. Elde edilen veriler doğrultusunda yılda 12 kitap ve altında kitap okuyan öğrenci sayısının 122, 12'den fazla kitap okuyanların sayısının ise 71 olduğu görülmüştür.

\section{Verilerin Analizi}

Araştırmadan elde edilen veriler, veri analizi paket programı yardımıyla analiz edilmiştir. Verilerin analiz yönteminin belirlenmesinde dağılım özellikleri esas alınmıştır. Büyüköztürk (2016), örneklem sayısının 50'nin üstünde olması durumunda dağılım özelliğini belirlemeye yönelik yapılabilecek testlerden Kolmogorov-Smirnov testinin dikkate alınması gerektiğini belirtmektedir. Bu sebeple dağılım özelliğinin test edildiği normallik testlerinden bu testin değeri esas alınmış ve normal dağılıma işaret eden diğer göstergeler (çarpıklık-basıklık katsayısı, z puanı gibi) de dikkate alınmıştır. Buna göre Sosyal Medya Bağımlılık Ölçeği'nden alınan puanların dağılım özellikleri incelendiğinde verilerin, öğrencilerin genel ağırlıklı not ortalamaları dikkate alındığında normal dağılım gösterdiği, sınıf düzeyi ve okunan kitap sayısına göre ise normal dağılmadığı tespit edilmiştir. Dolayısıyla sınıf öğretmenliği 
öğrencilerinin sosyal medya bağımlılığının sınıf düzeyine göre farklılaşıp farklılaşmadığının ortaya konulması amacıyla tek yönlü varyans analizinin nonparametrik karşılı̆̆ Sınıf öğretmenliği öğrencilerinin sosyal medya bağımlılık düzeylerinin genel ağırlıklı not ortalamasına göre anlamlı bir farklılık gösterip göstermediğinin test edilmesi amacıyla bağımsız örneklemler için $\mathrm{t}$ testi, okunan kitap sayısına göre farklılığın test edilmesi amacıyla da Mann Whitney U testi kullanılmıştır.

\section{Bulgular ve Yorum}

$\mathrm{Bu}$ bölümde yapılan analizler sonucunda elde edilen bulgular yer almaktadır. İlk olarak sınıf öğretmenliği öğrencilerinin sosyal medya bağımlılık düzeylerinin ne seviyede olduğunun ortaya konulması amacıyla frekans analizi yapılmışıtır. TutgunÜnal (2015) tarafından geliştirilen Sosyal Medya Bağımlılığı Ölçeği’nden alınan toplam puanın 41-73 arasında olması bağımlılığın olmadığını, 74-106 arasında olması bireyin az bağımlı olduğunu, 107-139 arasında olması orta bağımlı olduğunu, 140172 arasında olması yüksek bağımlı olduğunu ve 173-205 arasında olması ise çok yüksek bağımlı olduğunu göstermektedir. Buradan yola çıkarak elde edilen bulgular aşağıdaki tablodaki gibidir:

Tablo 1.

Sinıf Öğretmenliği Öğrencilerinin Sosyal Medya Bağımlılık Düzeyleri

\begin{tabular}{lcc}
\hline Bağımlıık düzeyi & Kişi sayısı & Yüzde (\%) \\
\hline Bağımlıık yok & 40 & 20,7 \\
\hline Az bağımı & 76 & 39,4 \\
\hline Orta bağımlı & 71 & 36,8 \\
\hline Yüksek bağımlı & 5 & 2,6 \\
\hline Çok yüksek bağımlı & 1 & 0,5 \\
\hline Toplam & 193 & 100 \\
\hline
\end{tabular}

Tablo 1 incelendiğinde örneklemi oluşturan 193 öğretmen adayından 40'ının sosyal medya bağımlılığının bulunmadığı, 76'sının az bağımlı, 71'inin ise orta bağımlı olduğu görülmektedir. Sosyal medya bağımlılık düzeyi yüksek ve çok yüksek olan sınıf öğretmeni adaylarının sayısının ise 6 olduğu görülmektedir. Buradan hareketle sınıf öğretmeni adaylarının çok büyük çoğunluğunun orta seviye ve altında bir bağımlılık düzeyine sahip olduğu söylenebilir. Ortalamanın üstünde bağımlılık düzeyine sahip öğrenci sayısının ise azlığı dikkat çekmektedir. Bu durumun, öğrencilerin ders yoğunluğundan kaynaklanabileceği düşünülmektedir. 
Sınıf öğretmeni adaylarının sosyal medya bağımlılık düzeyinin sınıf seviyesine göre farklılaşıp farklılaşmadığını ortaya koymak amacıyla Kruskal Wallis H testi yapılmıştır. Yapılan test sonucu elde edilen bulgular aşağıdaki tabloda yer almaktadır:

Tablo 2.

Kruskal Wallis H Testi Sonuçlart

\begin{tabular}{ccllll}
\hline Grup & $\mathbf{n}$ & Sira & Sd & $\mathbf{x}^{2}$ & $p$ \\
& & ortalaması & & & \\
\hline 2. Sinıf & 81 & 100,46 & 2 & 0,616 & 0,735 \\
3. Sinıf & 61 & 95,85 & & & \\
4. Sinıf & 51 & 92,87 & & & \\
\hline
\end{tabular}

Tablo 2 incelendiğinde sınıf öğretmenliği öğrencilerinin sosyal medya bağımlılık düzeylerinin sınıf seviyesine göre anlamlı bir farklılık göstermediği görülmektedir $\left(\mathrm{p}>0,05, x^{2} 3=0,616\right)$. Bu durumun, tüm öğrencilerin benzer yaş gruplarında yer almasından, dolayısıyla da aynı kuşağın çocukları olmasından kaynaklandığı düşünülmektedir.

Sınıf öğretmenliği öğrencilerinin sosyal medya bağımlılık düzeylerinin genel ağırlıklı not ortalamalarına göre anlamlı bir farklılık gösterip göstermediğini ortaya koymak amacıyla bağımsız gruplar için t testi yapılmıştır. Bu testten elde edilen sonuçlar aşağıdaki tabloda yer almaktadır.

Tablo 3.

Bağımsız Gruplar t Testi Sonuçları

\begin{tabular}{ccccccc}
\hline GANO & N & X & SS & Sd & t & $\boldsymbol{p}$ \\
\hline 3 ve altı & 101 & 96,72 & 27,73 & 191 &,- 500 &, 618 \\
3 üstü & 92 & 98,58 & 23,53 & & & \\
\hline
\end{tabular}

Tablo 3 incelendiğinde genel ağırlıklı not ortalaması 3'ün üzerinde olan öğrencilerin sosyal medya bağımlılık ölçeğinden aldıkları puanların aritmetik ortalamasının ( $\mathrm{X}=98.58)$, genel ağırlıklı not ortalaması 3 ve altında olan öğrencilere $(X=96.72)$ oranla daha yüksek olduğu fakat bu farkın anlamlı olmadığ gözlenmektedir (t191=-,500; p>0,05). Sosyal medya bağımlılık düzeyi yüksek öğrencilerin not ortalamasının daha yüksek olması, bu öğrencilerin sosyal medyayı eğitsel amaçlara yönelik kullanabileceği ve sosyal medya araçları vasıtasıyla etkileşim ve yardımlaşma içerisinde olabilecekleri ihtimaline dikkat çekmektedir. Aradaki farkın anlamlı olmaması ise bu durumun anlamlı fark yaratabilecek güçte olmadığının göstergesidir. 
Sınıf öğretmenliği öğrencilerinin sosyal medya bağımlılık düzeylerinin yllık ortalama olarak okudukları kitap sayısına göre farklılaşıp farklılaşmadığını ortaya koymak amacıyla ise Mann Whitney $\mathrm{U}$ testi yapılmıştır. $\mathrm{Bu}$ testten elde edilen bulgular aşağıdaki tabloda yer almaktadır:

Tablo 4.

Mann Whitney U Testi Sonuçları

\begin{tabular}{ccccccc}
\hline $\begin{array}{l}\text { Okunan kitap } \\
\text { sayısı }\end{array}$ & $\mathbf{n}$ & $\begin{array}{l}\text { Sira } \\
\text { ortalaması }\end{array}$ & Sira toplamı & $\mathbf{U}$ & $\mathbf{z}$ & $\boldsymbol{p}$ \\
\hline 12 ve altı & 122 & 103,75 & 12658,00 & 3507,00 & $-2,202$ &, 028 \\
12 üstü & 71 & 85,39 & 6063,00 & & & \\
\hline
\end{tabular}

Tablo 4 incelendiğinde, sınıf öğretmenlerinin sosyal medya bağımlılık düzeylerinin, yıllık ortalama olarak okunan kitap sayısına göre anlamlı bir farklılık gösterdiği sonucuna varılabilir $(\mathrm{p}<0,05)$. Bu farkı değerlendirebilme adına sıra ortalamaları incelendiğinde ise ylllk ortalama olarak 12 ve 12 'nin altında kitap okuyan öğrencilerin sıra ortalamasının 12'nin üstünde okuyan öğrencilere nazaran daha fazla olduğu görülmektedir. Buna göre y1llık olarak ortalama 12 ve altında kitap okuyan sınıf öğretmenliği öğrencilerinin sosyal medya bağımlılık ölçeğinden aldıkları puanların 12'nin üstünde okuyan öğrencilerden daha fazla olduğu, dolayısıyla bağımlılık düzeylerinin daha yüksek olduğu söylenebilir. Bu durum sosyal medyaya ayrılan süre arttıkça okunan kitap sayısının düştüğü şeklinde yorumlanabilir.

\section{Tartışma, Sonuç ve Öneriler}

Elde edilen bulgular incelendiğinde, sınıf öğretmeni adaylarının büyük bir çoğunluğunun sosyal medya bağımlılık düzeylerinin orta ve az seviyede olduğu görülmektedir. Çalışmaya dahil edilen beş öğrenciden birinin ise sosyal medya bağımlılığının bulunmadığı görülmüsştür. Sosyal medya bağımlılık seviyesi yüksek ve çok yüksek olan öğrencilerin ise azlığı dikkat çekmektedir. Bu alanda yapılan çalışmalar incelendiğinde ise bu araştırmada varılan bu sonuca paralel bulgular elde edilen çalışmaların varlığı göze çarpmaktadır. Aktan (2018) tarafından yapılan ve üniversite öğrencilerinin sosyal medya bağımlılık düzeylerini ortaya koymaya çalışan çalışmada üniversite öğrencilerinin sosyal medya bağımlılıklarının "az bağımlı" düzeyinde olduğu sonucuna varılmıştır. Çelik (2017) tarafından yapılan araştırmada da üniversite öğrencilerinin sosyal medya düzeyleri araştırılmış ve öğrencilerin sosyal medyaya az bağımlı oldukları sonucu ortaya konulmuştur.

Sınıf öğretmenliği adaylarının sosyal medya bağımlılık düzeylerinin sınıf düzeyine göre anlamlı bir farklılık göstermediği sonucuna varılmıştır. Çalışmaya dahil edilen ikinci, üçüncü ve dördüncü sınıf öğrencilerinin sosyal medya bağımlılık düzeyleri arasında anlamlı bir farklılık bulunmamakla birlikte bu üç grubun da ortalamalarına bakıldığında sosyal medyaya 'Az Bağımlı' (Tutgun-Ünal, 2015) 
oldukları söylenebilir. Bunlara ek olarak sınıf öğretmeni adaylarının SMBÖ’den aldıkları puanların ortalamalarının, sınıf seviyesi arttıkça düştüğü ve en düşük ortalama puana sahip grubun dördüncü sınıf öğrencileri olduğu söylenebilir. $\mathrm{Bu}$ durumun sebebine yönelik herhangi bir bulgu elde edilmemiş olmakla birlikte, dördüncü sınıf öğrencilerinin Kamu Personeli Seçme Sınavı'na hazırlanmalarının bu farka neden olduğu düşünülmektedir.

$\mathrm{Bu}$ araştırmanın alt problemlerinden bir diğeri sosyal medya bağımlılı̆̆ı ile akademik başarı arasındaki ilişkiyi incelemeye yöneliktir. Bu amaç doğrultusunda çalışmaya dahil edilen sınıf öğretmenliği öğrencileri, grupların denkliğinin sağlanabilmesi adına genel ağırlıklı not ortalaması üçün üstünde olanlar ve genel ağırlıklı not ortalaması üç ve altında olanlar olmak üzere iki gruba ayrılmış ve sosyal medya bağımlılık ölçeğinden aldıkları puanlar karşılaştırılmıştır. Elde edilen bulgular doğrultusunda not ortalamaları üçten yüksek olanlar ile düşük olanların sosyal medya bağımlılık düzeyleri arasında anlamlı bir farklılığın bulunmadığı sonucuna ulaşılmıştır. Buna ek olarak iki grubun sosyal medya bağımlılık ölçeğinden aldıkları puanların aritmetik ortalamaları incelendiğinde not ortalamaları üçten yüksek olan öğrencilerin sosyal medya bağımlılık ölçeğinden aldıkları puanların ortalamalarının not ortalaması üçten düşük olanlara oranla daha yüksek çıktığı da göze çarpmaktadır. Diğer bir ifadeyle elde edilen bulgular, sosyal medya bağımlılık düzeyi yüksek ögrencilerin daha yüksek not ortalamasına sahip olduğunu göstermektedir.

Sosyal medya kullanımı ve akademik başarı arasındaki ilişkiyi inceleyen çalışmalara bakıldığında literatürde yukarıdaki ifadeyi destekleyebilecek çalışmaların bulunduğu görülmektedir. Ainin, Naqshbandi, Moghavvemi ve Jaafar (2015) tarafından yapılan çalışmada, bir sosyal medya aracı olan Facebook'un kullanımı ile akademik başarı arasında pozitif yönde bir ilişkinin varlığı ortaya konulmuştur. $\mathrm{Bu}$ çalışmadan bir yıl sonra gerçekleştirilen bir başka çalışmada da Facebook, Twitter, ve Skype gibi sosyal medya sitelerinin kullanımının dikkati arttırdığı ve dolayısıyla da akademik başarıya pozitif yönde etki ettiği belirtilmiştir (Amin, Mansoor, Hussain \& Hashmat, 2016). Bunlara ek olarak Smith (2016), sosyal medyanın akademik başarı ile ilişkisini 'iki uçlu kılıç' benzetmesiyle ortaya koymuş ve sosyal medyanın, kullanım şekline göre akademik başarıyı hem arttırabilecek hem de azaltabilecek özelliklere sahip olabileceğini belirtmiştir. Smith'in ortaya koyduğu bulgulara benzer şekilde, sosyal medya ve akademik başarı arasında hiçbir bağın bulunmadığını, olayın tamamen zaman yönetimiyle alakalı olduğunu belirten başka araştırmacılar da bulunmaktadır (Alamri, 2019; Alwagait, Shahzad \& Alim, 2015).

Sosyal medya kullanımı ve akademik başarı arasındaki ilişkiyi inceleyen ulusal ve uluslararası literatür incelendiğinde, sosyal medya kullanımının akademik başarıyı olumsuz yönde etkilediğini belirten çalışmaların daha fazla olduğu göze çarpmaktadır (Al-Menayes, 2015; Apuke, 2016; Asemah vd., 2013; Chris, 2015; Çarkç1, 2019; Flanigan \& Babchuk, 2015; Giunchiglia vd., 2018; Habes vd., 2018; Leyrer-Jackson \& Wilson, 2018; Owusu-Acheaw \& Larson, 2015). Leyrer-Jackson ve Wilson (2018), 
kullanılan sosyal medya aracı sayısı arttıkça akademik başarının düştüğünü; Çarkçı (2019) da buna paralel olarak akademik başarı düzeyi arttıkça sosyal bağımlılık düzeyinin azaldığını belirtmiştir. Ayrıca sosyal medya kullanımının üniversite öğrencilerinin akademik başarılarına etki eden faktörleri negatif yönde etkilediği ve dolayısıyla da akademik başarıyı etkilediği belirtilmektedir (Giunchiglia ve arkadaşları, 2018). Bunlara ek olarak sosyal medya kullanımı ile akademik başarı arasında doğrudan bir ilişki olduğu ve sosyal medya kullanımının akademik başarıyı düşürücü etkiye sahip olduğu yapılan nicel araştırmalarla ortaya konmuş (Asemah vd., 2013; Apuke, 2016; Chris, 2015; Habes vd., 2018; Owusu-Acheaw \& Larson, 2015) ve bu durum literatürde yer alan nitel araştırmalarla da desteklenmiştir (Flanigan \& Babchuk, 2015). Bu araştırmada elde edilen bulgular göz önünde bulundurulduğunda, aradaki fark anlamlı olmamasına karşın not ortalaması yüksek öğrencilerin sosyal medya bağımlılık düzeylerinin not ortalaması düşük öğrencilere oranla daha yüksek olduğu sonucuna varılmıştır. Bahsi geçen araştırmaların bulgularının bu çalışmaya paralel olduğu söylenebilir.

$\mathrm{Bu}$ araştırmanın alt amaçlarından bir diğeri de sosyal medya bağımlllık düzeyinin okunan kitap sayısına göre yorumlanabilmesini sağlayacak verilerin elde edilmesidir. Yapılan analizler sonucunda ayda bir kitaptan fazla okuyan öğrencilerin sosyal medya bağımlılık düzeylerinin ayda bir kitap ve daha azını okuyan öğrencilere oranla anlamlı bir şekilde daha düşük olduğu sonucuna varılmışıtır. Başka bir ifadeyle daha az kitap okuyan sınıf öğretmenliği öğrencilerinin sosyal medya bağımlılık düzeyleri daha yüksek olmaktadır. Literatür incelendiğinde, sosyal medya ve kitap okuma alışkanlığ 1 arasındaki ilişkiyi inceleyen çalışmaların çok az olduğu görülmektedir. Karadeniz ve Can'ın (2015) yapmış olduğu çalı̧̧mada okuma alışkanlıkları ve sosyal medya kullanımı arasında negatif bir korelasyondan bahsedilmektedir. Buna göre, sosyal medya kullanımı arttıkça okunan kitap sayısının azaldığı belirtilmektedir. $\mathrm{Bu}$ araştırmada da Karadeniz ve Can (2015) tarafindan yapılan korelasyonel çalışmaya benzer sonuçlara ulaşıldığı söylenebilir.

Çalışma kapsamında ulaşılan sonuçlar ışı̆̆ında şu önerilerde bulunulabilir: Kitap okuma oranı yüksek öğrencilerin sosyal medya bağımlılığının düşük olduğu göz önünde bulundurulduğunda sınıf öğretmenliği öğrencilerinin kitap okumaya teşvik edilmesi önerilebilir. Bu amaçla lisans derslerinde dersi veren öğretim üyeleri bu anlamda yönlendirmeler yapabilir, kitap kulüpleri kurulabilir. Sosyal medyanın aynı zamanda eğitsel amaçlı da kullanılabileceği bilindiğinden sınıf öğretmenliği öğrencilerine yönelik bu kapsamda bir bilgilendirme toplantısı veya eğitim düzenlenebilir. Bununla birlikte tüm üniversite öğrencilerinin sosyal medya bağımlılıklarının daha farklı değişkenlere göre incelenmesini hedefleyen araştırmaların yapılmasının alana katkı sağlayabileceği düşünülmektedir.

\section{Çıkar Çatışması ve Etik Bildirimi}

Yazarlar aralarında çıkar çatışması bulunmadığını beyan etmiş̧ir. Yazarlar tüm etik kurallara uyduklarını bildirmiştir. 


\section{Kaynakça}

Ahn, J. (2011). Digital divides and social network sites: Which students participate in social media? Journal of Educational Computing Research, 45(2) 147-163. https://doi.org/10.2190/EC.45.2.b

Ainin, S., Naqshbandi, M.M., Moghavvemi, S., \& Jaafar, N.I. (2015). Facebook usage, socialization and academic performance. Computers \& Education, 83, 64-73. https://doi.org/10.1016/j.compedu.2014.12.018

Akar, E. (2010). Sosyal medya pazarlamast: Sosyal Webde pazarlama stratejileri. Elif Yayınevi.

Aktan, E. (2018). Üniversite öğrencilerinin sosyal medya bağımlılık düzeylerinin çeşitli değişkenlere göre incelenmesi. Erciyes Iletişim Dergisi, 5(4), 405-421. https://doi.org/10.17680/erciyesiletisim.379886

Alamri, M.M. (2019). Undergraduate students' perceptions toward social media usage and academic performance: A study from Saudi Arabia. International Journal of Emerging Technologies in Learning (iJET), 14(3), 61-79. https://doi.org/10.3991/ijet.v14i03.9340

Alican, C., \& Saban, A. (2013). Ortaokul ve lise de öğrenim gören öğrencilerin sosyal medya kullanımına ilişkin tutumları: Ürgüp örneği. Sosyal Bilimler Enstitüsü Dergisi, 1(35), 1-14.

Al-Menayes, J.J. (2015). Social media use, engagement and addiction as predictors of academic performance. International Journal of Psychological Studies, 7(4), 86-94. doi: :10.5539/ijps.v7n4p86

Alwagait, E., Shahzad, B., \& Alim, S. (2015). Impact of social media usage on students academic performance in Saudi Arabia. Computers in Human Behavior, 51, 1092-1097. https://doi.org/10.1016/j.chb.2014.09.028

Amin, Z., Mansoor, A., Hussain, S.R., \& Hashmat, F. (2016). Impact of social media of student's academic performance. International Journal of Business and Management Invention, 5(4), 22-29.

Apuke, O.D. (2016). The influence of social media on academic performance of undergraduate students of Taraba state university, Jalingo, Nigeria. Res. Humanit. Soc. Sci, 6(19), 63-72. doi: $10.29333 / \mathrm{ojcmt} / 2615$

Asemah, E.S., Okpanachi, R.A., \& Edegoh, L.O. (2013). Influence of social media on the academic performance of the undergraduate students of Kogi State University, Anyigba, Nigeria. Research on Humanities and Social Science, 3(12), 90-96.

Aydın, İ.E. (2016). Üniversite öğrencilerinin sosyal medya kullanımları üzerine bir araştırma: Anadolu Üniversitesi örneği. Selçuk Üniversitesi Sosyal Bilimler Enstitüsü Dergisi, 35 , 373-386.

Balcı, Ş., \& Gölcü, A. (2013). Facebook addiction among university students in Turkey: Selcuk University example. Türkiyat Araştırmaları Dergisi, 34, 255-278.

Bat, M. (2012). Dijital platformda sosyal medyanın stratejik kurumsal iletişime etkisi (Tez No. 302862) [Doktora tezi, Ege Üniversitesi-İzmir]. Yükseköğretim Kurulu Başkanlığı Tez Merkezi.

Best, J.W., \& Kahn, J.V. (2017). Eğitimde araştırma yöntemleri. O. Köksal (Çev. Ed.). Dizgi Ofset.

Brown, E. (2012). Working the crowd: Social media marketing for business. British Informatics Society Limited.

Büyüköztürk, Ş. (2016). Sosyal Bilimler için veri analizi el kitabı: Ístatistik, araştırma deseni SPSS uygulamalart ve yorum (Genişletilmiş 22. Baskı). Pegem Akademi Yayıncılık.

Can, A. (2018). SPSS ile bilimsel araştırma sürecinde nicel veri analizi. Pegem Akademi Yayınc1lik. 
Chris, L.A. (2015). Influence of social media on study habits of undergraduate students in Kenyan universities. International Journal of Novel research in Humanity and Social Sciences, 2(4), 42-55.

Çam, E., \& İşbulan, O. (2012). A new addiction for teacher candidates: Social networks. Turkish Online Journal of Educational Technology, 11(3), 14-19.

Çarkçı, Z. (2019). Üniversite öğrencilerinde sosyal medya bağımlılı̆̆ının çeşitli değişkenler açısından incelenmesi (Tez No. 570411) [Yüksek lisans tezi, Ufuk Üniversitesi-Ankara]. Yükseköğretim Kurulu Başkanlığı Tez Merkezi.

Çelik, M. (2017, 5-6 Mayıs). Üniversite öğrencilerinin sosyal medya bağımlılık düzeylerinin incelenmesi: Kültür Üniversitesi öğrencileri üzerinde bir araştırma. 1. Uluslararası İletişimde Yeni Yönelimler Konferansinda sunulan bildiri, İstanbul Ticaret Üniversitesi, İstanbul, Türkiye.

Ellison, N.B., \& Boyd, D. (2013). Sociality through social network sites. In W.H. Dutton (Ed.), The Oxford handbook of internet studies (p. 151-172). Oxford University Press. doi: 10.1093/oxfordhb/9780199589074.013.0008

Ergenç, A. (2011). Web 2.0 ve sanal sosyalleşme: Facebook örneği (Tez no. 278725) [Yüksek lisans tezi, Maltepe Üniversitesi-İstanbul].Yükseköğretim Kurulu Başkanlığı Tez Merkezi.

Flanigan, A.E., \& Babchuk, W.A. (2015). Social media as academic quicksand: A phenomenological study of student experiences in and out of the classroom. Learning and Individual Differences, 44, 40-45. http://dx.doi.org/10.1016/j.lindif.2015.11.003

Giunchiglia, F., Zeni, M., Gobbi, E., Bignotti, E., \& Bison, I. (2018). Mobile social media usage and academic performance. Computers in Human Behavior, 82, 177-185. doi: 10.1016/j.chb.2017.12.041

Greenhow, C. (2011). Youth, learning, and social media. Journal of Educational Computing Research, 45(2), 139-146. https://doi.org/10.2190/EC.45.2.a

Gruzd, A., Staves, K., \& Wilk, A. (2012). Connected scholars: Examining the role of social media in research practices of faculty using the UTAUT Model. Computers in Human Behavior, 28, 2340-2350. doi: 10.1016/j.chb.2012.07.004

Günay, M. (2017). Să̆lıkla ilgili fakültelerde eğitim görenlerin sosyal medya bağımlılık düzeyi (Tez No. 502134) [Yüksek lisans tezi, Trakya Üniversitesi-Edirne]. Yükseköğretim Kurulu Başkanlığı Tez Merkezi.

Habes, M., Alghizzawi, M., Khalaf, R., Salloum, S.A., \& Ghani, M.A. (2018). The relationship between social media and academic performance: Facebook perspective. International Journal of Information Technology and Language Studies, 2(1), 12-18.

İçirgin, Ö. (2018). Üniversite ögrrencilerinin sosyal medya kullanım alışkanlıkları ve motivasyonları (Tez No. 503264) [Yüksek lisans tezi, Selçuk Üniversitesi-Konya]. Yükseköğretim Kurulu Başkanlığı Tez Merkezi.

İliş, A. (2018). Ĕgitim fakültesi ögrrencilerinin sosyal medya bă̆ımlılı̆̆ ile iletişim becerileri arasındaki ilişskinin farklı değişkenler açısından incelenmesi (Tez No. 524487) [Yüksek lisans tezi, Atatürk Üniversitesi-Erzurum]. Yükseköğretim Kurulu Başkanlığı Tez Merkezi.

Joosten, T. (2012). Social media for educators: Strategies and best practices. Jossey-Bass.

Kaplan, A.M., \& Haenlein, M. (2010). Users of the world, unite! the challenges and opportunities of social media. Business Horizons, 53(1), 59-68. doi: 10.1016/j.bushor.2009.09.003

Karadeniz, A., \& Can, R. (2015). A research on book reading habits and media literacy of students at the faculty of education. Procedia-Social and Behavioral Sciences, 174, 40584067. doi: $10.1016 /$ j.sbspro.2015.01.1155 
Karal, H., \& Kokoç, M. (2010). Üniversite öğrencilerinin sosyal ağ siteleri kullanım amaçlarını belirlemeye yönelik bir ölçek geliştirme çalışması. Turkish Journal of Computer and Mathematics Education, 1(2), 251-263.

Karasar, N. (2014). Bilimsel araştırma yöntemleri: kavramlar, teknikler ve ilkeler (Genişletilmiş 27. Baskı). Nobel Yayınevi.

Kıroğlu, K. (2014). Eğitimle ilgili temel kavramlar. K. Kıroğlu \& C. Elma (Ed.), Eğitim bilimine giriş içinde (s. 2-17). Pegem Akademi Yayıncılık.

Kilmen, S. (2015). Ĕgitim araştırmacıları için SPSS uygulamalı istatistik. Edge Akademi.

Kuss, D.J., \& Griffiths, M.D. (2011). Online social networking and addiction-a review of the psychological literature. International Journal of Environmental Research and Public Health, 8(9), 3528-3552. doi: 10.3390/ijerph8093528

Küçükali, A. (2016). Üniversite öğrencilerinin sosyal medya kullanımı: Atatürk Üniversitesi örneği. Bartın Üniversitesi İ.̇.B.F. Dergisi, 7(13), 531-546.

Leyrer-Jackson, J.M., \& Wilson, A.K. (2018). The associations between social-media use and academic performance among undergraduate students in biology. Journal of Biological Education, 52(2), 221-230. https://doi.org/10.1080/00219266.2017.1307246

Mason, R., \& Rennie, F. (2008). Learning and social networking handbook: Resources for higher education. (1st Edition). Routledge. https://doi.org/10.4324/9780203927762

Owusu-Acheaw, M., \& Larson, A.G. (2015). Use of social media and its impact on academic performance of tertiary institution students: A study of students of Koforidua Polytechnic, Ghana. Journal of Education and Practice, 6(6), 94-101. https://doi.org/10.1016/j.sjbs.2021.01.010

Özşahin, C. (2019). Öğretmenlerin sosyal medya bă̆ımlılı̆̆l, ögrretmenlik özyeterlilikleri ve motivasyonları arasındaki ilişkinin incelenmesi (Tez No. 538075) [Yüksek lisans tezi, Gaziantep Üniversitesi-Gaziantep]. Yükseköğretim Kurulu Başkanlığı Tez Merkezi.

Ravenscroft, A. (2009). Social software,Web 2.0 and learning: status and implications of an evolving paradigm. Journal of Computer Assisted Learning, 25(1), 1-5. https://doi.org/10.1111/j.1365-2729.2008.00308.x

Sarsar, F., Başbay, M., \& Başbay, A. (2015). Öğrenme-öğretme sürecinde sosyal medya kullanımı. Mersin Üniversitesi Ĕgitim Fakültesi Dergisi, 11(2), 418-431. doi: 10.17860/efd. 98783

Scott, D.M (2010). The new rules of marketing and PR (5. Edition). John Wiley and Sons.

Smith, E.E. (2016). A real double-edged sword: Undergraduate perceptions of social media in their learning. Computers \& Education, 103, 44-58. https://doi.org/10.1016/j.compedu.2016.09.009

Solmaz, B., Tekin, G., Herzem, Z., \& Demir, M. (2013). İnternet ve sosyal medya kullanımı üzerine bir uygulama. Selçuk İletişim Dergisi, 7(4), 23-32. doi:10.18094/si.92009

Soysal, S.D. (2019). Sinıf ögrretmenlerinin sosyal medyada ögrretmen-ögrrenci etkileşimine yönelik görüşleri (Tez No. 551061) [Yüksek lisans tezi, Abant İzzet Baysal ÜniversitesiBolu]. Yükseköğretim Kurulu Başkanlığı Tez Merkezi.

Tuncer, S. (2013). Sosyal medyanın gelişimi. Z. Özata (Ed.), Sosyal medya içinde (s.2-25). Anadolu Üniversitesi Yayınları.

Tutgun-Ünal, A. (2015). Sosyal medya bă̆ımlılı̆̆l: Üniversite öğrencileri üzerine bir araștırma (Tez No. 396821) [Doktora tezi, Marmara Üniversitesi-İstanbul]. Yükseköğretim Kurulu Başkanlığı Tez Merkezi.

Vural, Z.B.A., \& Bat, M. (2010). Yeni bir iletişim ortamı olarak sosyal medya: Ege Üniversitesi İletişim Fakültesine yönelik bir araştırma. Journal of Yasar University, 20(5), 3348-3382. doi:10.19168/jyu.65130 
Yılmazsoy, B., \& Kahraman, M. (2017). Üniversite öğrencilerinin sosyal medya bağımlılı̆̆g ile sosyal medyayı eğitsel amaçlı kullanımları arasındaki ilişkinin incelenmesi: Facebook örneği. Journal of Instructional Technologies \& Teacher Education, 6(1), 9-20.

\section{Extended Abstract}

Social media platforms have become an important part of Web 2.0 technology (Karal \& Kokoç, 2010). In fact, some researchers argue that the concepts of "Web 2.0" and "social media" (Mason \& Rennie, 2008) or those of "Web 2.0" and "social software" (Ellison \& Boyd, 2013; Ravenscroft, 2009) can be used interchangeably. Brown (2012) defines Web 2.0 as social web. All these definitions hint that Web 2.0-based virtual platforms play a key role in the way we communicate.

Technology has increasingly focused on the relationship between the individual and society, which has significantly transformed the way people communicate and paved the way for a new way of socializing (Aydın, 2016). Today, social platforms are venues where people make new friends, establish new business contacts, and even get married (Özşahin, 2019). Social media platforms are becoming more and more popular venues where young people in particular use to communicate (Ahn, 2011). Social media platforms have a significant impact on large masses and people of different age groups because they allow people in different time zones and places to communicate through words, images, and videos (Soysal, 2019).

Studies in Turkey also report data on the correlation between social media use and age. İçirgin (2018) found that most university students use social media frequently. On the other hand, Aydin (2016) conducted research on more than 4000 participants and concluded that the vast majority of Internet users are those aged 16-24 years and that there is a significant correlation between Internet use and social media use. Considering the fact that especially high school and university students use social media frequently, we believe that it is of paramount important to investigate the advantages and disadvantages of social media in terms of education for people aged 16-24 years.

There are studies investigating the correlation between social media and education in different age groups. There are, however, no studies investigating the relationship between social media addiction, academic performance, and reading habit among preservice classroom teachers. We, therefore, believe that our results will contribute to the literature.

The aim of this study was to investigate the effect of grade level, GPA, and the number of books they read per year on social media addiction among preservice classroom teachers. To this end, the study sought answers to the following subquestions:

1) What is the level of social media addiction among preservice classroom teachers? 
2) Does preservice classroom teachers' social media addiction significantly differ by grade level?

3) Does preservice classroom teachers' social media addiction significantly differ by GPA?

4) Does preservice classroom teachers' social media addiction significantly differ by the average number of books they read in a year?

A screening model was used in this study to determine participants' social media addiction levels. In screening models, the event, individual or object of interest is analyzed as it is or was (Karasar, 2014).

The study population consisted of all second-, third-, and fourth- grade students of the department of classroom education of a public university in Samsun in the fall term of the 2019-2020 academic year. No sampling was performed because we were able to reach the entire study population.

Data were collected using the Social Media Addiction Scale (SMAS) developed by Tutgun-Ünal (2015) to measure social media addiction among university students. The SMAS is a 5-point Likert type scale consisting of 41 items and four subscales. The scale score ranges from 41 to 205. Tutgun-Ünal (2015) recruited 775 university students to establish the scale validity and reported a Cronbach's alpha of .967 . Participants' GPAs and the average number of books they read in a year were also determined. Participants were divided into two groups based on GPA with a cut-off point of 3 .

The Kruskal Wallis $\mathrm{H}$ test was used to determine the effect of grade level on participants' social media addiction levels. A t test for independent samples was used to determine the effect of GPA on their social media addiction levels. The Mann Whitney U test was used to determine the effect of the number of books read in a year on participants' social media addiction levels.

Most of our participants had little to moderate social media addiction. Both Aktan (2018) and Çelik (2017) reported little social media addiction among university students.

Participants with a GPA greater than 3 had a higher arithmetic SMAS score than those with a GPA less than 3, which was however statistically insignificant. Some of the studies on the correlation between social media use and academic performance support our result. Ainin et al. (2015) reported a positive correlation between Facebook use and academic performance. Amin et al (2016) also found that people using social media platforms, such as Facebook, Twitter, and Skype, had longer attention spans, and therefore, better academic performance. Smith (2016) uses the metaphor of "two-edged sword" to describe the relationship between social media use and academic performance and argues that social media platforms can either increase 
or reduce academic performance, depending on the way they are used. Similar to Smith's results, there are studies arguing that there is no correlation between social media and academic performance but that it depends solely on time management (Alwagait, Shahzad \& Alim, 2015; Alamri, 2019).

National and international studies generally show that social media use results in a reduction in academic performance (Flanigan \& Babchuk, 2015; Leyrer-Jackson \& Wilson, 2018; Giunchiglia et al., 2018; Owusu-Acheaw \& Larson, 2015; Al-Menayes, 2015; Asemah, Okpanachi \& Edegoh, 2013; Chris, 2015; Habes et al., 2018; Apuke, 2016; Çarkç1, 2019). Leyrer-Jackson ve Wilson (2017) reported that the higher the number of social media platforms the students use, the lower their academic performance. In parallel to this, Çarkçı (2019) found that the higher the students' academic performance, the lower their social media use.

Participants who read more than one book per month had significantly lower SMAS scores than those who read one book or less per month. In other words, participants who read less have higher social media addiction. 